\title{
Seven New Species of Spiders of the Subfamily Coelotinae (Araneae: Agelenidae) from Kyushu, Japan
}

\author{
Ken-ichi Okumura \\ Nagasaki Prefectural Isahaya Senior High School, \\ Higashikoji-machi 1-7, Isahaya-shi, Nagasaki 854-0014, Japan \\ E-mail:coelotes@hor.bbiq.jp
}

(Received 18 June 2012; Accepted 25 December 2012)

\begin{abstract}
Seven new species of the subfamily Coelotinae are described from Kyushu, Japan, under the names Coelotes unzenensis sp. nov., C. saikaiensis sp. nov., C. koshikiensis sp. nov., C. iriei sp. nov., C. oxyacanthus sp. nov., Draconarius verrucifer sp. nov., and D. dialeptus sp. nov. Coelotes unzenensis sp. nov. and C. saikaiensis sp. nov. are unique in comparison with all the known Japanese coelotine spiders with two exceptions, Alloclubionoides grandivulva (Yaginuma, 1969) and C. motobuensis (Shimojana, 2000), in lacking the patellar apophysis of the male palpus. Coelotes koshikiensis sp. nov. has genital organs similar to those of C. gotoensis Okumura, 2007 and is endemic to the Koshiki Islands, Kagoshima Prefecture. Coelotes iriei sp. nov. has genital organs similar to those of C. decolor Nishikawa, 1973, and these two species are closely related. Coelotes oxyacanthus sp. nov. resembles C. hiradoensis Okumura and Ono, 2006. This new species is endemic to the Goto Islands, Nagasaki Prefecture. Draconarius verrucifer sp. nov. is distinguished from the other known coelotine spiders from Japan by having a small protrusion on the epigynum. Draconarius dialeptus sp. nov. is found only on Yaku Island, Kagoshima Prefecture. Its male palpal structure is similar to that of some other species of Draconarius, including D. aspinatus Wang, Yin, Peng, and Xie, 1990, D. bituberculatus Wang, Yin, Peng, and Xie, 1990, and D. venustus Ovtchinnikov, 1999. In this paper, $D$. verrucifer sp. nov. is described based only on females, $D$. dialeptus sp. nov. on males, and the other new species on both sexes.
\end{abstract}

Key Words: Taxonomy, Araneae, Coelotinae, Coelotes, Draconarius, new species, Kyushu, Japan.

\section{Introduction}

Spiders of the subfamily Coelotinae are restricted to the Northern Hemisphere. More than 600 species have been described, especially from East Asia (Platnick 2012). In Japan, 111 species have been known up to the present (Okumura et al. 2009, 2011; Okumura 2010). Coelotine spiders generally live on the ground, being found under stones, logs, and leaf litter; some cave-dwelling species are also known. Species in this group tend to show regional distribution and geographical variation because most of the species do not disperse by ballooning. Therefore, it is believed that many unidentified or undescribed species remain.

Nishikawa (2009) described 44 new species of Japanese spiders in the subfamily Coelotinae, largely from Honshu and Shikoku. Three of the 44 species, viz., Coelotes ikiensis Nishikawa, 2009, C. osamui Nishikawa, 2009, and C. exilis Nishikawa, 2009, were added to the fauna of Kyushu and its surrounding islands, with the latter two species being endemic to Yaku Island. These finds suggest that many unknown coelotine spiders might be discovered in this region.

My survey of Kyushu and neighboring islands in recent years has yielded a number of species that are new to science. Some have already been described (Okumura and Ono 2006; Okumura 2007), while others have remained undescribed due to the small number of samples or absence of both sexs. In this paper, with additional material in hand,
I describe seven new species of the subfamily Coelotinae from Kyushu and surrounding islands as members of the genera Coelotes Blackwall, 1841 and Draconarius Ovtchinnikov, 1999.

\section{Materials and Methods}

Specimens were examined and illustrated using an Olympus SZX-7 stereomicroscope. All measurements are given in millimeters. Leg measurements are given as total length (femur, patella plus tibia, metatarsus, and tarsus). Abbreviations used in this paper are as follows: ALE, anterior lateral eye; AME, anterior median eye; LTA, lateral tibial apophysis; MOA, median ocular area; PLE, posterior lateral eye; PME, posterior median eye; RTA, retrolateral tibial apophysis.

All the specimens were collected by K. Okamura if not otherwise indicated. Type specimens of the new species described in this paper have been deposited in the collections of the Department of Zoology, National Museum of Nature and Science, Tsukuba (NSMT).

Coelotes unzenensis sp. nov. [Japanese name: Unzen-yachigumo]

(Fig. 1A-D)

Material examined. Holotype. NSMT-Ar 9848, male, Mt. Kusenbu, $620 \mathrm{~m}$ alt., Unzen city, Nagasaki Prefecture 

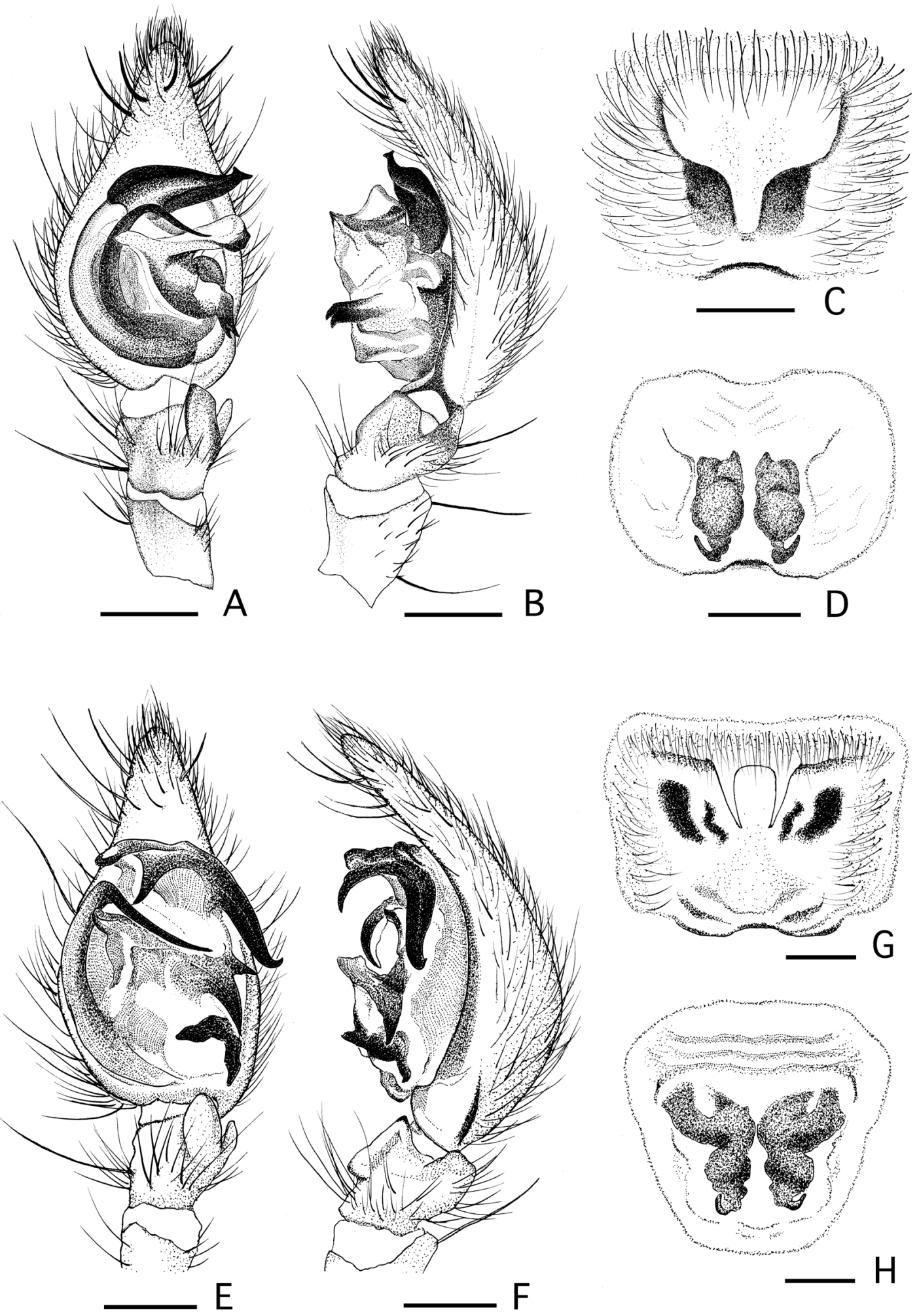

Fig. 1. A-D, Coelotes unzenensis sp. nov.; E-H, C. saikaiensis sp. nov. A-B, NSMT-Ar 9848, holotype, male; C-D, NSMT-Ar 9849, allotype, female; E-F, NSMT-Ar 9852, holotype, male; G-H, NSMT-Ar 9853, paratype, female. A, E, Male palpus, ventral view; B, F, same, retrolateral view; C, G, epigynum; D, H, internal female genitalia. Scales: $0.5 \mathrm{~mm}$.

(32 $\left.{ }^{\circ} 78.6^{\prime} \mathrm{N}, 130^{\circ} 25.8^{\prime} \mathrm{E}\right), 24$ September 2005.

Allotype. NSMT-Ar 9849, female, Chijiwacho, $210 \mathrm{~m}$ alt., Unzen city, Nagasaki Prefecture, 12 March 2005.

Paratypes. NSMT-Ar 9850, 1 male, same data as the holotype; NSMT-Ar 9851, 1 female, Mt. Kinugasa, $710 \mathrm{~m}$ alt., Unzen city, Nagasaki Prefecture, 12 March 2005.
Non-type specimens. All the specimens were collected from Nagasaki Prefecture. Notori, Chijiwacho, Unzen city: 1 female, 12 March 2005; 1 female, 3 December 2005. Tashirobaru pasture, $610 \mathrm{~m}$ alt., Unzen city: 2 females, 12 March 2005; 1 male, 24 September 2005. Ikenohara, $760 \mathrm{~m}$ alt., Unzen city: 1 female, 12 March 2005. Shirakumo Pond, 
$710 \mathrm{~m}$ alt., Unzen city: 1 female, 12 March 2005. Issaigyo falls, $600 \mathrm{~m}$ alt., Unzen city: 1 female, 7 October 2005. Mt. Azuma, $650 \mathrm{~m}$ alt., Unzen city: 2 females, 8 October 2005. Mt. Kusenbu, $820 \mathrm{~m}$ alt., Unzen city: 1 male and 1 female, 3 December 2005. Mt. Iwaya, $210 \mathrm{~m}$ alt., Nagasaki city: 1 male, 8 December 2006; 4 females, 12 February 2006. Mt. Konpira, $230 \mathrm{~m}$ alt., Nagasaki city: 3 females, 4 March 2006. Mt. Kabuto, $280 \mathrm{~m}$ alt., Nagasaki city: 1 male, 24 September 2011. Narumidai, $110 \mathrm{~m}$ alt., Nagasaki city: 1 male, 9 October 2011. Sakikoba, Sonodamachi, Nagasaki city: 1 female, 9 October 2011. Kibachimachi, Nagasaki city: 1 male, 3 October 2011; 2 males and 2 females, 23 October 2011. Kashirakubi, Nishiumicho, Nagasaki city: 1 male and 6 females, 7 December 2011. Azekaricho, Nagasaki city: 2 females, 7 December 2011. Hirakoba, Iimoricho, Isahaya city: 1 male, 1 October 2011. Goban-no-tsuji, Iimoricho, Isahaya city: 1 female, 1 October 2011. Mt. Kotono-o, $405 \mathrm{~m}$ alt., Nagayo town, Nishisonogi county: 1 female, 19 February 2006.

Diagnosis. Coelotes unzenensis sp. nov. resembles C. bifurcatus Okumura and Ono, 2006 (q.v.) in the structure of the male palpus, i.e., in having a sword-shaped conductor outgrowth process, a broad conductor, an anteriorly originating embolus, a bifurcate median apophysis, and a broad, shallow atrium, but can be easily distinguished from the latter species by the absence of a patellar apophysis in the male palpus and the absence of epigynal teeth.

Description. Holotype (male). Total length 10.6, carapace 5.6 long, 3.8 wide; abdomen 5.0 long, 3.4 wide; sternum 2.9 long, 2.1 wide. Eye sizes: AME 0.17, ALE 0.24, PME 0.20, PLE 0.19. Distances between eyes: AME-AME 0.07, AME-ALE 0.06, PME-PME 0.09, PME-PLE 0.24, AMEPME 0.10, ALE-PLE 0.04. MOA: anterior width 0.41, posterior width 0.49 , length 0.47 . Leg measurements: I, 15.0 (4.2, 5.2, 3.6, 2.0); II, 13.8 (3.9, 4.5, 3.4, 2.0); III, 12.8 (3.7, 4.0, 3.4, 1.7); IV, 17.3 (4.6, 5.4, 5.0, 2.3).

Cheliceral promargin with one tooth on left and three teeth on right, and both retromargins with two teeth.

Palpus (Fig. 1A, B): patellar apophysis absent; LTA corniculate; RTA broad and flat; cimbial furrow short and indistinctive; median apophysis claw-shaped and slightly bifurcate; conductor robust and somewhat twisted; embolus thick and short.

Coloration: carapace blackish brown with gray radial flecks; dorsum of abdomen blackish brown, with grayishbrown irregular flecks; sternum reddish brown; chelicerae, maxillae, and labium reddish black; legs blackish brown, without ring flecks.

Allotype (female). Total length 16.0, carapace 6.5 long, 4.3 wide; abdomen 9.5 long, 6.4 wide; sternum 3.2 long, 2.4 wide. Eye sizes: AME 0.17, ALE 0.26, PME 0.23, PLE 0.24. Distances between eyes: AME-AME 0.17, AME-ALE 0.14, PME-PME 0.16, PME-PLE 0.34, AME-PME 0.22, ALEPLE 0.10. MOA: anterior width 0.51 , posterior width 0.62 , length 0.62. Leg measurements: I, 14.3 (4.1, 4.8, 3.4, 2.0); II, 13.7 (4.0, 4.6, 3.2, 1-9); III, 12.7 (3.5, 4.0, 3.3, 1.9); IV, 17.4 $(4.5,5.7,5.0,2.2)$.

Cheliceral promargin with three teeth and retromargin with two.

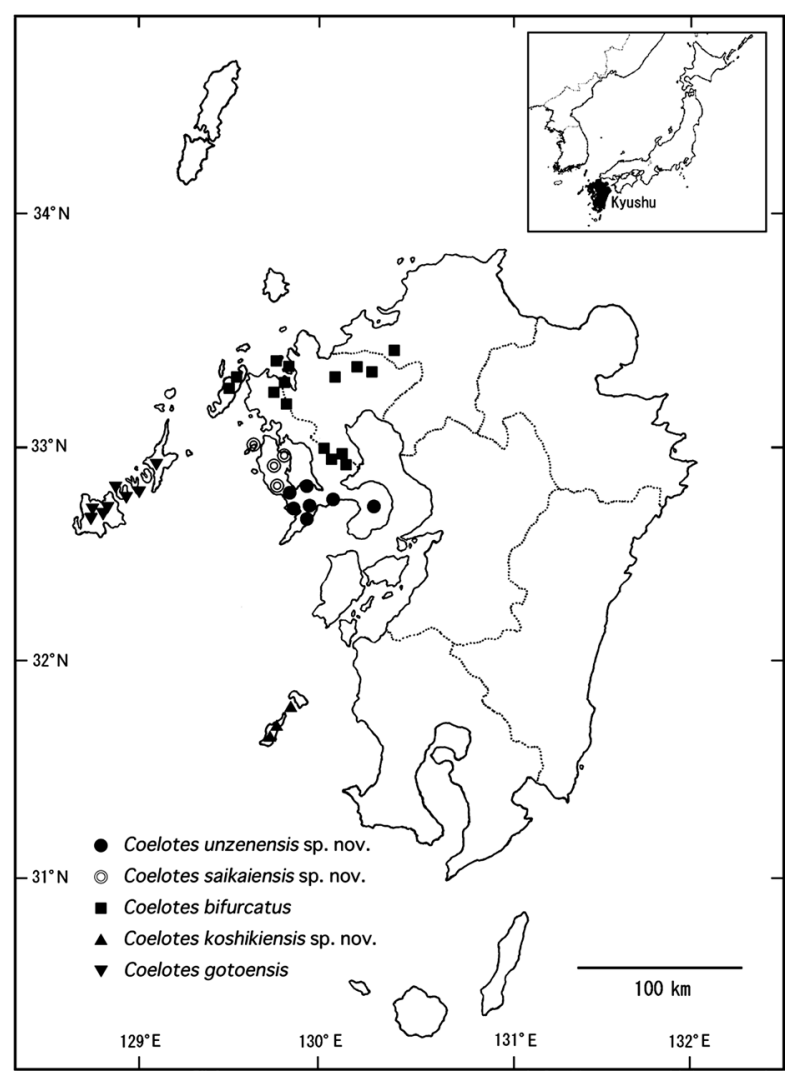

Fig. 2. Map of Kyushu, Japan, showing the distribution of Coelotes unzenensis sp. nov., C. saikaiensis sp. nov., C. koshikiensis sp. nov., and their allied species, C. bifurcates Okumura and Ono, 2006 and C. gotoensis Okumura, 2007.

Epigynum and endogynum (Fig. 1C, D): central portion of epigynal plate funnel-shaped and protuberate; copulatory opening with black circumference, situated posterior to epigynum; epigynal teeth absent; spermathecae roundish, situated close to each other.

Coloration almost same as that of male holotype.

Distribution. Nagasaki Prefecture (Fig. 2). Coelotes unzenensis sp. nov is distributed from Mt. Unzen to Nagasaki city and its environs. It is thus allopatric with respect to $C$. saikaiensis sp. nov., which inhabits the Nishisonogi Peninsula and Oshima island (see below).

Etymology. The specific name, an adjective, is derived from the type locality.

Coelotes saikaiensis sp. nov. [Japanese name: Saikai-yachigumo] (Fig. 1E-H)

Material examined. Holotype. NSMT-Ar 9852, male, Mt. Yuri, $110 \mathrm{~m}$ alt., Seihi-Oshima island, Nagasaki Prefecture $\left(33^{\circ} 04.0^{\prime} \mathrm{N}, 129^{\circ} 60.6^{\prime} \mathrm{E}\right), 2$ November 2008.

Paratypes. NSMT-Ar 9853-9854, 2 females, same data as the holotype.

Non-type specimens. All the specimens were collected from Nagasaki Prefecture. Type locality: 1 female, 24 November 2007; 2 females, 30 December 2007; 1 male and 1 female, 2 November 2008. Mt. Kashii, 370 m alt., Saikai city: 
1 female, 30 December 2007. Mt. Shira, $200 \mathrm{~m}$ alt., Saikai city: 1 male, 11 October 2009. Nagasaki Bio Park, Seihicho, Saikai city: 1 male, 20 November 2011. Koh-no-ura, Sotomecho, Nagasaki city: 3 males and 1 female, 9 October 2011. Katsurayama, Nishiumicho, Nagasaki city: 1 male, 9 October 2011. Hiratoko, Nishiumicho, Nagasaki city: 1 female, 20 November 2011.

Diagnosis. Coelotes saikaiensis sp. nov. resembles C. unzenensis sp. nov. in the absence of a patellar apophysis in the male palpus, but can be distinguished from the latter species by other structures of the genital organ in both sexes. The conductor of C. saikaiensis is obliquely elongated in the direction of the base of the cymbium, but that of C. unzenensis is elongated in the direction of the tip of cymbium. Large epigynal teeth exist in C. saikaiensis but are absent in C. unzenensis.

Description. Male (holotype). Total length 10.9; carapace 5.6 long, 3.9 wide; abdomen 5.3 long, 3.3 wide; sternum 2.9 long, 2.2 wide. Eye sizes: AME 0.17, ALE 0.25, PME 0.20, PLE 0.20. Distances between eyes: AME-AME 0.11, AME-ALE 0.08, PME-PME 0.14, PME-PLE 0.27, AMEPME 0.14, ALE-PLE 0.09. MOA: anterior width 0.45, posterior width 0.54 , length 0.51 . Leg measurements: I, 15.6 (4.2, 5.5, 3.8, 2.1); II, 14.1 (3.9, 4.8, 3.4, 2.0); III, 12.6 (3.4, 4.0, 3.4, 1.8); IV, $17.3(4.5,5.7,5.1,2.0)$.

Cheliceral promargin with three teeth and retromargin with two.

Palpus (Fig. 1E, F): patellar apophysis absent; LTA small; RTA broad and flat; conductor bifurcate, ventral part with spine-like outgrowth, and dorsal one slightly curved and obliquely pointing in direction of base of cymbium; embolus thick and short.

Coloration: carapace brown, with gray radial flecks; dorsum of abdomen gray, with yellowish-brown chevrons; sternum reddish brown; chelicerae, maxillae, and labium blackish brown; legs brown, without ring flecks.

Female (paratype, NSMT-Ar 9853). Total length 11.4; carapace 5.3 long, 3.6 wide; abdomen 6.1 long, 3.9 wide; sternum 2.6 long, 2.2 wide. Eye sizes: AME 0.13, ALE 0.25, PME 0.25, PLE 0.20. Distances between eyes: AME-AME 0.10, AME-ALE 0.13, PME-PME 0.15, PME-PLE 0.33, AMEPME 0.15, ALE-PLE 0.03. MOA: anterior width 0.35, posterior width 0.55 , length 0.48 . Leg measurements: I, 14.4 (4.0, 5.2, 3.3, 1.9); II, 12.8 (3.5, 4.5, 3.0, 1.8); III, 12.0 (3.3, 3.8, 3.2, 1.7); IV, $16.5(4.3,5.5,4.7,2.0)$.

Cheliceral promargin with three teeth and retromargin with two.

Epigynum and endogynum (Fig. 1G, H): epigynal teeth acuminate, conglutinated with thin plate, situated in anterior portion of epigynum; spermathecae narrow in middle, consisting of large anterior portion and small posterior one; copulatory ducts broad, covering whole region of genitalia.

Coloration almost same as that of male holotype.

Distribution. Nagasaki Prefecture (Nishisonogi Peninsula and Oshima island) (Fig. 2).

Etymology. The specific name, an adjective, is derived from the type locality.

\author{
Coelotes koshikiensis sp. nov. \\ [Japanese name: Koshikijima-yachigumo]
}

(Fig. 3A-D)

Material examined. Holotype. NSMT-Ar 9855, male, Sesenoura, $405 \mathrm{~m}$ alt., Shimokoshiki Island, Kagoshima Prefecture $\left(31^{\circ} 71.6^{\prime} \mathrm{N}, 129^{\circ} 72.2^{\prime} \mathrm{E}\right), 30$ December 2011.

Paratypes. NSMT-Ar 9856, 1 female, same data as the holotype; NSMT-Ar 9857, 1 female, Sesenoura, $140 \mathrm{~m}$ alt., Shimokoshiki Island, Kagoshima Prefecture, 30 December 2011.

Non-type specimens. All were collected from the Koshiki Islands, Kagoshima Prefecture. Nakakoshiki Island: Mt. Kinokuchi, $220 \mathrm{~m}$ alt., 2 females, 29 December 2011. Shimokoshiki Island: Sesenoura, $140 \mathrm{~m}$ alt., 2 females, 30 December 2011; Sesenoura, $300 \mathrm{~m}$ alt., 1 male, 30 December 2011; Sesenoura, $400 \mathrm{~m}$ alt., 1 female, 30 December 2011; Nagahama, $220 \mathrm{~m}$ alt., 1 female, 31 December 2011; Mt. Otake, $200 \mathrm{~m}$ alt., 1 male and 2 females, 31 December 2011.

Diagnosis. Coelotes koshikiensis sp. nov. resembles $C$. gotoensis Okumura, 2007 (q.v.) in having a large and darkcolored body, a large patellar apophysis, and epigynal teeth arising from the anterior margin of the epigynum. These two species can be distinguished from each other by the structure of the genital organs in both sexes. The conductor outgrowth process is developed and the tip of the patellar apophysis is expanded in C. koshikiensis, but those of $C$. gotoensis are neither developed nor expanded. The epigynal teeth are quite long and narrow in C. koshikiensis, but short in C. gotoensis.

Description. Male (holotype, NSMT-Ar 9855). Total length 9.5; carapace 5.3 long, 3.4 wide; abdomen 4.2 long, 2.7 wide; sternum 2.7 long, 2.0 wide. Eye sizes: AME 0.08, ALE 0.18, PME 0.11, PLE 0.13. Distances between eyes: AME-AME 0.05, AME-ALE 0.03, PME-PME 0.09, PMEPLE 0.13, AME-PME 0.10, ALE-PLE 0.04. MOA: anterior width 0.21 , posterior width 0.31 , length 0.29 . Leg measurements: I, 14.6 (4.0, 5.0, 3.5, 2.1); II, 12.9 (3.6, 4.3, 3.1, 1.9); III, 12.1 (3.4, 4.0, 3.2, 1.5); IV, 16.6 (4.3, 5.3, 4.9, 2.1).

Cheliceral promargin with three teeth and retromargin with two.

Palpus (Fig. 3A, B): patellar apophysis expanded at tip and as long as patella; LTA reduced; cymbial furrow short, one-fourth of length of cymbium; conductor short and tripartite with large conductor outgrowth process; embolus short.

Coloration: carapace blackish brown with indistinct radial flecks; ocular area darker; dorsum of abdomen dark gray with yellowish-brown chevrons; sternum brown; chelicerae, maxillae, and labium reddish brown; legs blackish brown with indistinct ring flecks.

Female (paratype, NSMT-Ar 9856). Total length 13.0; carapace 5.8 long, 3.7 wide; abdomen 7.2 long, 4.7 wide; sternum 2.9 long, 2.3 wide. Eye sizes: AME 0.09, ALE 0.18, PME 0.14, PLE 0.14. Distances between eyes: AME-AME 0.08, AME-ALE 0.06, PME-PME 0.10, PME-PLE 0.18, AMEPME 0.13, ALE-PLE 0.08. MOA: anterior width 0.26 , posterior width 0.38 , length 0.36 . Leg measurements: I, 16.2 (4.2, 

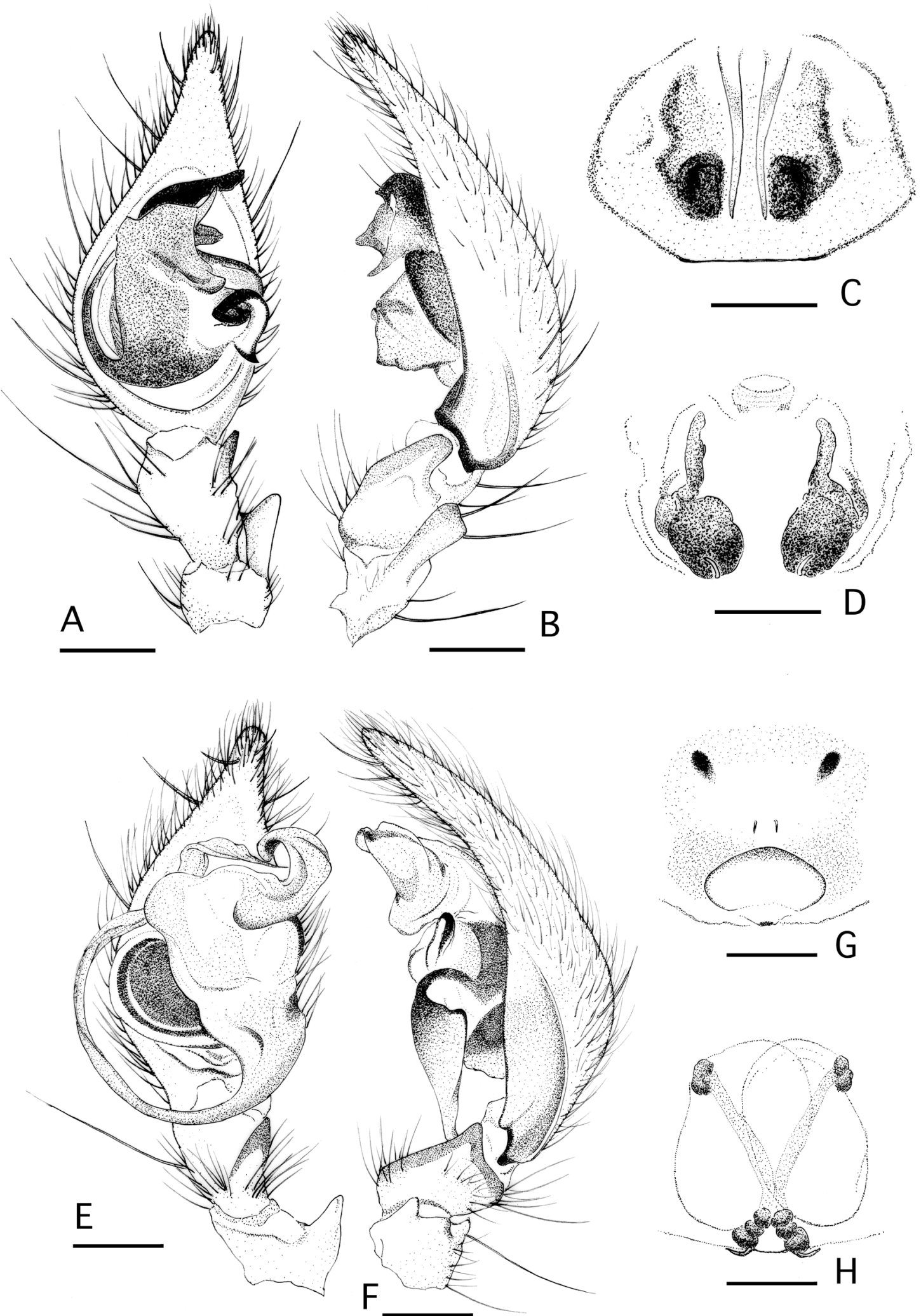

Fig. 3. A-D, Coelotes koshikiensis sp. nov.; E-H, C. iriei sp. nov. A-B, NSMT-Ar 9856, holotype, male; C-D, NSMT-Ar 9855, paratype, female; E-F, NSMT-Ar 9858, holotype, male; G-H, NSMT-Ar 9859, allotype, female. A, E, Male palpus, ventral view; B, F, same, retrolateral view; $C, G$, epigynum; $D, H$, internal female genitalia. Scales: $0.5 \mathrm{~mm}$.

5.4, 4.1, 2.5); II, 14.3 (3.9, 4.5, 3.8, 2.1); III, 13.2 (3.6, 4.0, 3.7, 1.9); IV, $17.5(4.5,5.5,5.3,2.2)$.

Cheliceral promargin with three teeth and retromargin with two.
Epigynum and endogynum (Fig. 3C, D): epigynal plate almost hexagonal; copulatory openings situated on lateral sides of central portion of epigynum; epigynal teeth long and narrow, situated in anterior portion of epigynum close 
to each other; spermathecae distant from each other, anterior portion somewhat elongated, posterior part expanded.

Coloration almost same as that of male paratype.

Distribution. Koshiki Islands, Kagoshima Prefecture (Fig. 2).

Etymology. The specific name, an adjective, is derived from the type locality.

\section{Coelotes iriei sp. nov. \\ [Japanese name: Haiiro-yachigumo]}

(Fig. 3E-H)

Material examined. Holotype. NSMT-Ar 9858, male, Mt. Mie, 290 m alt., Honmyocho, Kagoshima city, Kagoshima Prefecture $\left(31^{\circ} 69.6^{\prime} \mathrm{N}, 130^{\circ} 52.5^{\prime} \mathrm{E}\right), 27$ December 2010.

Allotype. NSMT-Ar 9859, female, same data as holotype.

Paratypes. NSMT-Ar 9860, 1 male, Mt. Hinamori, 590 m alt., Kobayashi city, Miyazaki Prefecture, 12 October 2006; NSMT-Ar 9861, 1 female, Takachiho, $1200 \mathrm{~m}$ alt., Makizonocho, Kirishima city, Kagoshima Prefecture, 8 October 2007.

Non-type specimens. Kumamoto Prefecture: Tsunoyama, Amakusa-shimojima island, 1 male, 25 December 2003, T. Irie leg.; Minakami village, Kuma county, 1 male, 3 October 2009, T. Irie leg. Kagoshima Prefecture: same locality as NSMT-Ar 9861, 4 females, 13 October 2006, 1 female, 4 January 2010; Kirishima-taguchi, $890 \mathrm{~m}$ alt., Kirishima city, 1 female (3 January 2010), 1 female (26 December 2010); Kirishima-taguchi, $850 \mathrm{~m}$ alt., Kirishima city, 1 female, 4 January 2010; Mt. Mie, 1 male and 3 females, same data as holotype; Ohira, Kimotsuki town, Kimotsuki county, 1 female, 29 December 2010; Mt. Hassan, $450 \mathrm{~m}$ alt., Kanoya city, 1 male and 2 females, 29 December 2010; Yamadono, $150 \mathrm{~m}$ alt., Nagashima island, 1 female, 27 December 2011; Nishime, Akune city, 1 male, 27 December 2011; Fukata, $150 \mathrm{~m}$ alt., Ichiki-kushikino city, 1 female, 28 December 2011; Sato, Kamikoshiki Island, 1 female, 29 December 2011; Oshima, $80 \mathrm{~m}$ alt., Shimokoshiki Island, 1 female, 29 December 2011; Seo, Shimokoshiki Island, 1 male, 30 December 2011; Katanoura, $270 \mathrm{~m}$ alt., Shimokoshiki Island, 1 male and 1 female, 30 December 2011; Ashihama, Shimokoshiki Island, 1 female, 31 December 2011; Imuta, Kashima town, Shimokoshiki Island, 1 female, 31 December 2011. Miyazaki Prefecture: Ebino plateau, $1165 \mathrm{~m}$ alt., Ebino city, 2 females, 8 October 2007; Minamimata, $150 \mathrm{~m}$ alt., Aya town, Higashimorokata county, 1 female, 3 January 2010; Toguchi, $500 \mathrm{~m}$ alt., Miikecho, Miyakonojo city, 1 female, 3 January 2010.

Diagnosis. Coelotes iriei sp. nov. resembles C. decolor Nishikawa, 1973 (q.v.) in having a pale body, a broad and strongly curved conductor of the male palpus, and minute epigynal teeth, but can be distinguished from the latter species by the genital structure. The embolus of the male palpus of $C$. iriei becomes thin and spirally curved towards the tip, but that of C. decolor is not spiral. The epigynum of $C$. iriei is deeply hollowed in its posterior portion exactly as in cybaeid spiders, but that of $C$. decolor is not hollow.

Description. Holotype (male). Total length 11.5; carapace 5.8 long, 4.0 wide; abdomen 5.7 long, 3.3 wide; sternum 3.0 long, 2.3 wide. Eye sizes: AME 0.15, ALE 0.23, PME 0.20, PLE 0.25. Distances between eyes: AME-AME 0.10, AME-ALE 0.10, PME-PME 0.15, PME-PLE 0.23, AME-PME 0.15, ALE-PLE 0.08. MOA: anterior width 0.40, posterior width 0.55 , length 0.50 . Leg measurements: I, 18.3 $(4.8,6.1,4.5,2.9)$; II, 16.3 (4.4, 5.3, 4.0, 2.6); III, 15.3 (3.9, $4.7,4.2,2.5)$; IV, $21.0(5.4,6.4,6.1,3.1)$.

Cheliceral promargin with three teeth on left and four on right, and both retromargins with two teeth.

Palpus (Fig. 3E, F): patellar apophysis short; LTA absent; RTA broad; cymbial furrow elongated, about half as long as cymbial length; median apophysis large, spoon-like; conductor broad, spiraled with one loop; embolus enlarged, deeply grooved at origin in lateral view, irregularly crooked, and pointed at tip.

Coloration: carapace yellowish brown, with brown radial flecks; dorsum of abdomen gray, with indistinct chevrons; sternum yellowish brown; chelicerae and labium brown; maxillae reddish brown; leg I brown, leg II yellowish brown, legs III and IV yellowish grey; legs lacking ring flecks.

Female (allotype). Total length 12.2; carapace 5.3 long, 3.3 wide; abdomen 6.9 long, 4.1 wide; sternum 2.5 long, 2.1 wide. Eye sizes: AME 0.13, ALE 0.23, PME 0.18, PLE 0.20. Distances between eyes: AME-AME 0.10, AME-ALE 0.13, PME-PME 0.15, PME-PLE 0.25, AME-PME 0.10, ALEPLE 0.08. MOA: anterior width 0.36 , posterior width 0.51 , length 0.41. Leg measurements: I, 14.6 (4.1, 5.0, 3.3, 2.2); II, 13.2 (3.7, 4.3, 3.2, 2.0); III, 12.7 (3.4, 3.9, 3.4, 2.0); IV, 17.2 $(4.6,5.3,4.9,2.4)$.

Cheliceral promargin with three teeth and retromargin with two.

Epigynum and endogynum (Fig. 3G, H): atrium small but deeply hollowed; epigynal teeth thin, minute, situated on central plate of epigynum; spermathecal head transparent, visible as single blackish-brown dot at anterior region of epigynum; spermathecae long, X-shaped, connected to spermathecal heads and fertilization ducts; copulatory ducts broad, oval-shaped, medially overlapping each other.

Coloration of carapace and abdomen almost same as that of male holotype; leg I brown, leg II yellowish brown, legs III and IV yellowish grey; legs lacking ring flecks.

Distribution. Kumamoto, Kagoshima, and Miyazaki Prefectures (Fig. 4).

Etymology. The specific name, a noun in the genitive case, is dedicated to Mr. Teruo Irie, who discovered this new species in 2003.

Remark. The coloration and the epigynal form of the new species are dissimilar from those of the type species of Coelotes. It is, nonetheless, placed in Coelotes because its most closely related species, Coelotes decolor, is also classified in this genus (Nishikawa 1973).

Coelotes oxyacanthus sp. nov. [Japanese name: Togeboso-yachigumo] (Fig. 5A-D)

Material examined. Holotype. NSMT-Ar 9862, female, 


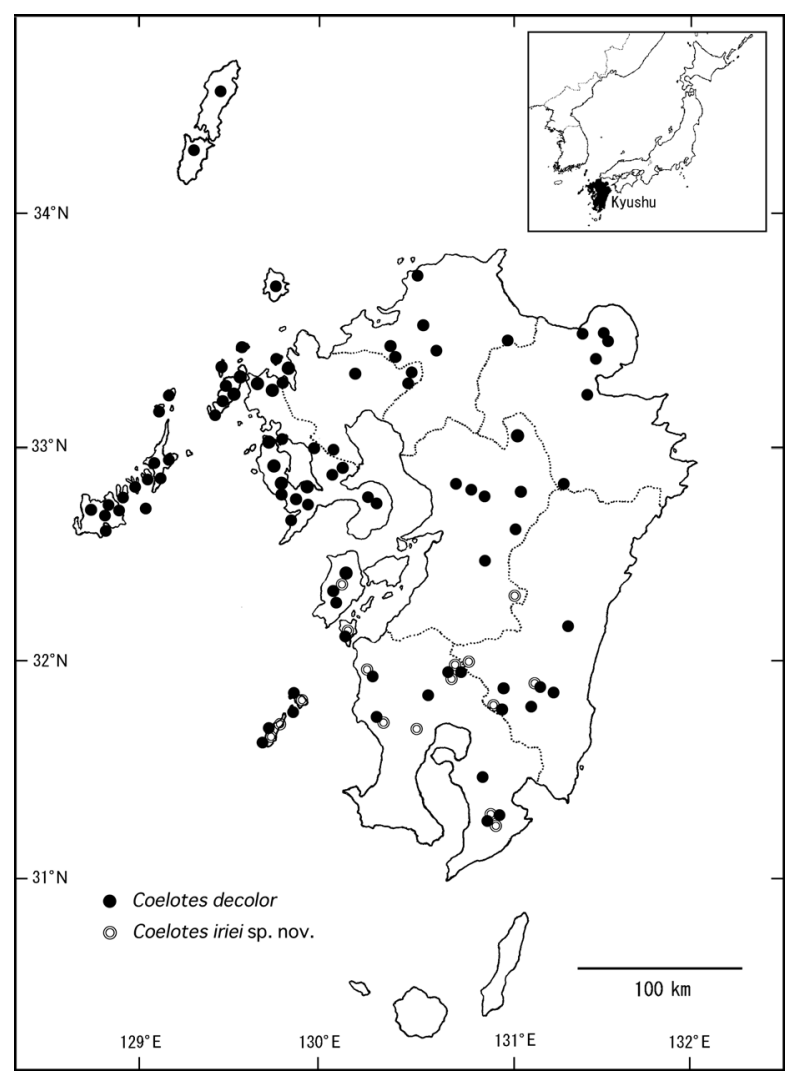

Fig. 4. Map of Kyushu, Japan, showing the distribution of Coelotes iriei sp. nov, described in the present paper and its allied species, Coelotes decolor Nishikawa, 1973.

Arikawa, Nakadori Island, Goto Islands, Nagasaki Prefecture $\left(32^{\circ} 93.0^{\prime} \mathrm{N}, 129^{\circ} 04.3^{\prime} \mathrm{E}\right), 8$ February 2009.

Paratypes. NSMT-Ar 9863, 1 male, Arakawa, Nakadori Island, Goto Islands, Nagasaki Prefecture, 8 February 2009; NSMT-Ar 9864, 1 female, Mt. Ryukan, $120 \mathrm{~m}$ alt., Wakamatsu Island, Goto Islands, Nagasaki Prefecture, 7 February 2009.

Non-type specimens. All the specimens were collected from the Goto Islands, Nagasaki Prefecture. Ohiraki, Hisaka Island: 1 male, 29 November 2008. Mt. Ryukan, $120 \mathrm{~m}$ alt., Wakamatsu Island: 1 female, 7 February 2009. Mt. Tetega, $150 \mathrm{~m}$ alt., Fukue Island: 1 female, 14 February 2009; 1 female, 8 November 2009. Okunokoba, Fukue Island: 1 female, 10 January 2010. Koumu, Kishikucho, Fukue Island: 1 male, 6 November 2010. Mt. San-no, 320 m alt., Nakadori Island: 1 male, 24 January 2010.

Diagnosis. Coelotes oxyacanthus sp. nov. resembles $C$. hiradoensis Okumura and Ono, 2006 (q.v.) in its small-sized body, having short cymbium, long embolus, and slender epigynal teeth. These two seem to be sister species, but the former can be distinguished from the latter by the following points. The conductor of the palpus is short and branched in C. oxyacanthus, but that of C. hiradoensis is elongated in the direction of the tip of the cymbium. The epigynal teeth on the anterior portion are distant from each other in C. oxyacanthus, but close together in C. hiradoensis.

Description. Male (paratype, NSMT-Ar 9863). Total length 6.2; carapace 3.2 long, 2.1 wide; abdomen 3.0 long,
2.0 wide; sternum 1.6 long, 1.3 wide. Eye sizes: AME 0.09, ALE 0.18, PME 0.13, PLE 0.13. Distances between eyes: AME-AME 0.04, AME-ALE 0.05, PME-PME 0.04, PMEPLE 0.13, AME-PME 0.09, ALE-PLE 0.04. MOA: anterior width 0.22 , posterior width 0.30 , length 0.31 . Leg measurements: I, 8.1 (2.3, 2.9, 1.9, 1.0); II, 7.3 (2.1, 2.5, 1.7, 1.0); III, $6.7(1.9,2.1,1.8,0.9)$; IV, $9.2(2.5,3.0,2.6,1.1)$.

Cheliceral promargin with three teeth and retromargin with two.

Palpus (Fig. 5A, B): patellar apophysis bifurcate; LTA broad; RTA not sharp; cymbial furrow elongate, occupying two-thirds of cymbial length; anterior edge of conductor complexly branched; embolus long and slender, arising in 5-oclock position of cymbium as viewed from ventral side.

Coloration: carapace yellowish brown; dorsum of abdomen grayish brown, with yellowish-brown chevrons; sternum yellowish brown; chelicerae, maxillae, and labium brown; legs yellowish brown, without ring flecks.

Female (holotype). Total length 7.5; carapace 3.5 long, 2.0 wide; abdomen 4.0 long, 2.8 wide; sternum 1.5 long, 1.3 wide. Eye sizes: AME 0.08, ALE 0.18, PME 0.14, PLE 0.13. Distances between eyes: AME-AME 0.04, AME-ALE 0.08, PME-PME 0.06, PME-PLE 0.15, AME-PME 0.10, ALEPLE 0.05. MOA: anterior width 0.20 , posterior width 0.34 , length 0.32. Leg measurements: I, 7.2 (2.1, 2.6, 1.6, 0.9); II, $6.6(1.9,2.3,1.5,0.9)$; III, $5.7(1.7,1.9,1.4,0.7)$; IV, 8.2 (2.3, $2.7,2.2,1.0)$.

Cheliceral promargin with three teeth, and retromargin with three teeth on left and two on right.

Epigynum and endogynum (Fig. 5C, D): anterior portion M-shaped, with thin sclerotized frames on both sides; posterior portion blackish; epigynal teeth long, acute, widely separated; spermathecae situated in posterior portion of epigynum, distant from each other; copulatory ducts long and strongly convoluted.

Coloration almost same as that of male paratype.

Distribution. Goto Islands, Nagasaki Prefecture (Fig. 6).

Etymology. The specific name is a compound noun in the nominative singular, derived from the Latin prefix $o x y$, "sharp, acute", and acanthus, "spine", referring to the long and acute epigynal teeth in the new species.

Remark. The genital structures in both sexes of the new species are dissimilar from those of the type species of the genus Coelotes. It is, nonetheless, placed in Coelotes because its three most closely related species, C. hiradoensis, C. sawadai, and C. taurus, are also classified in this genus (Okumura and Ono 2006; Nishikawa 2009).

\section{Draconarius verrucifer sp. nov.} [Japanese name: Higo-yachigumo]

(Fig. 5E-H)

Material examined. Holotype. NSMT-Ar 9865, female, Minami-aso village, Aso county, Kumamoto Prefecture (coordinates unknown), 18 February 1990, Yoh Ihara leg.

Paratype. NSMT-Ar 9866, same as holotype, 1 female, 17 February 1990, Yoh Ihara leg. 

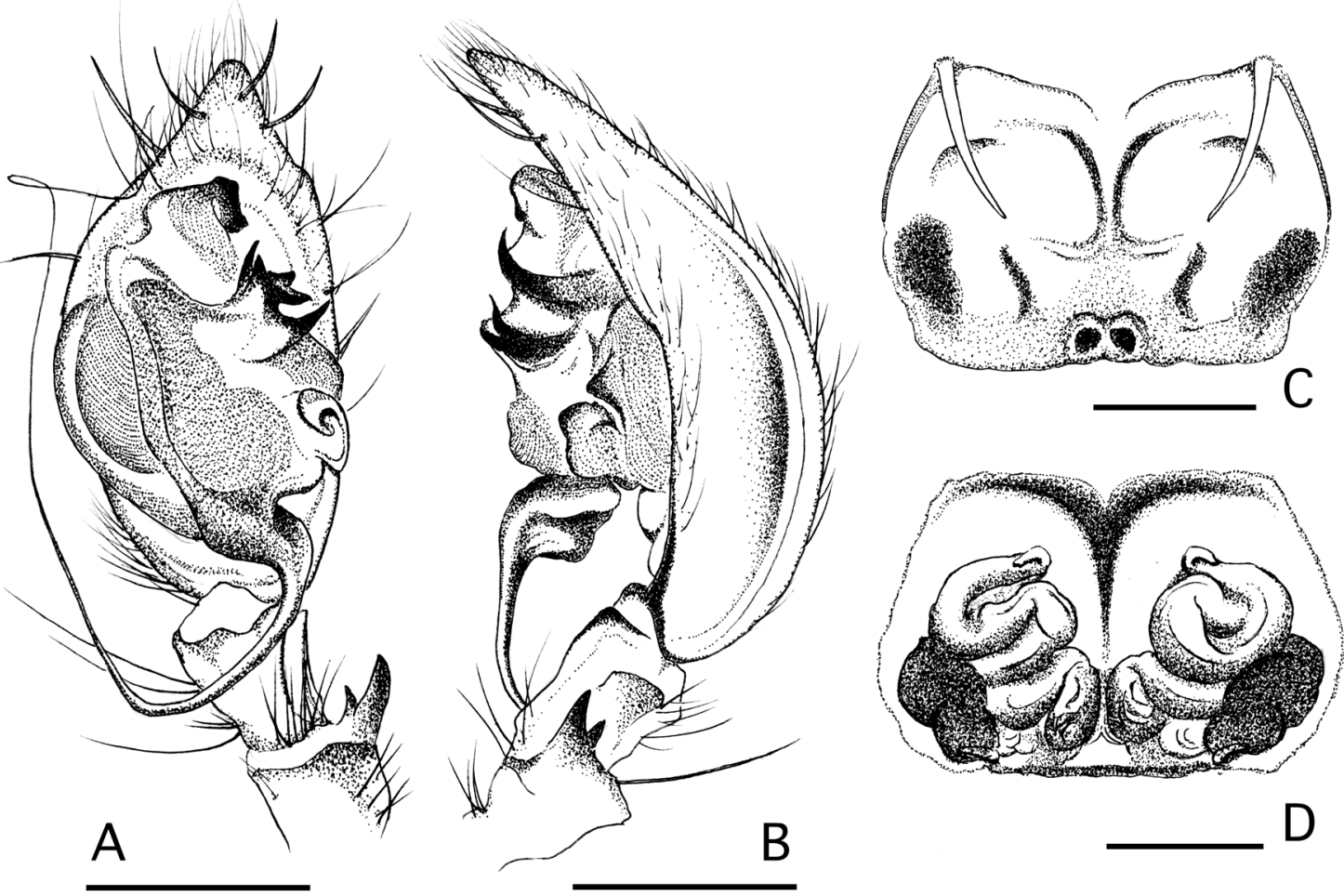

B
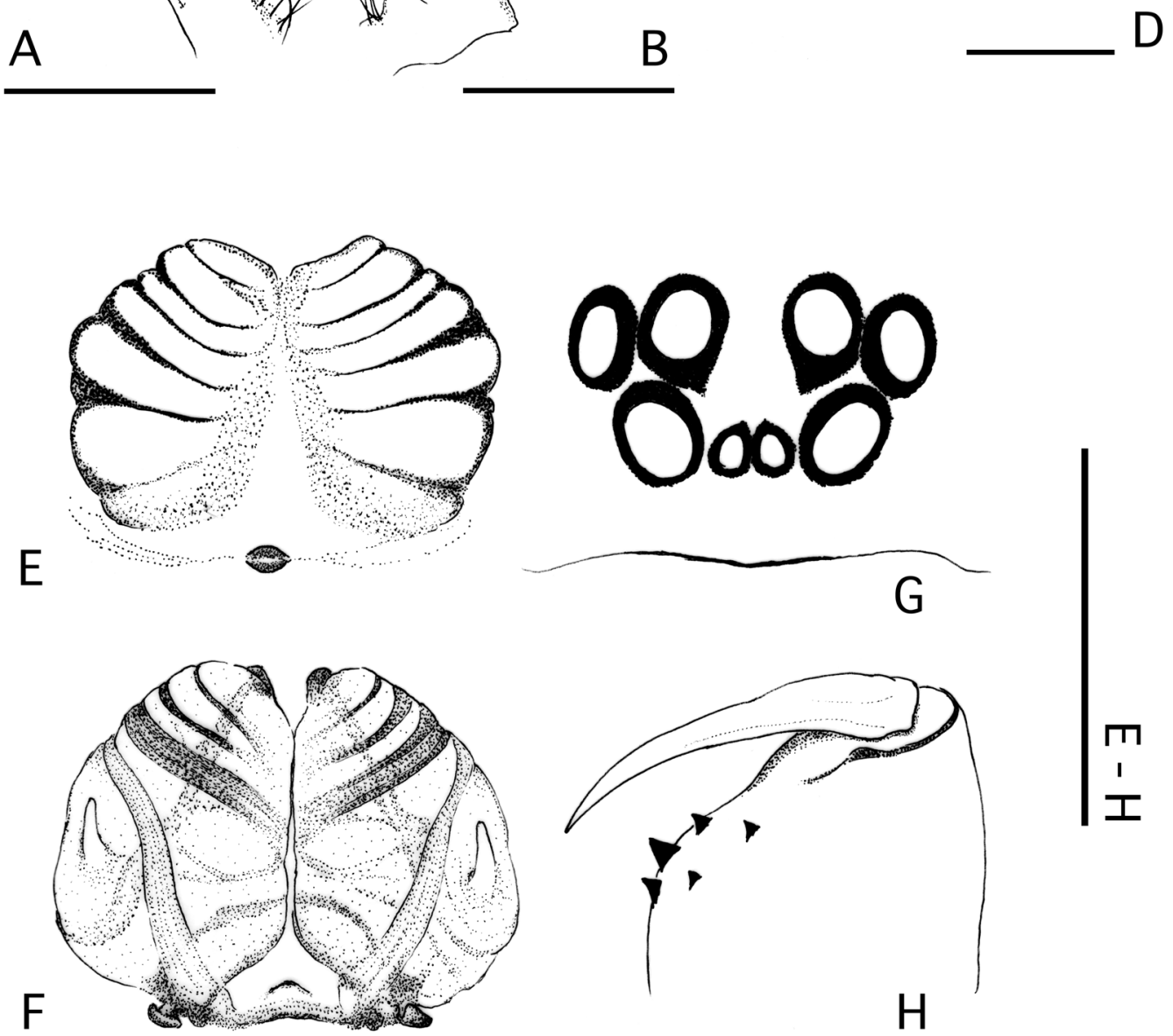

Fig. 5. A-D, Coelotes oxyacanthus sp. nov.; E-H, Draconarius verrucifer sp. nov. A-B, NSMT-Ar 9863, paratype, male; C-D, NSMT-Ar 9862, holotype, female; E-H, NSMT-Ar 9865, holotype, female. A, Male palpus, ventral view; B, same, retrolateral view; C, E, epigynum; D, F, internal female genitalia; $G$, ocular area, frontal view; $\mathrm{H}$, left chelicera, ventral view. Scales: $0.5 \mathrm{~mm}$.

Non-type specimens. Kikuchi-keikoku, Kikuchi city, Kumamoto Prefecture, 1 female, 16 February 1990, Yoh Ihara leg.; Izumimachi, Yatsushiro county, Kumamoto Prefecture, 2 females, 28 March 2001, Yoh Ihara leg.; northern area of
Mt. Sobo, Oita Prefecture, 1 female, 27 August 2007, Shingo Hatsushiba leg.

Diagnosis. The new species belongs to the Draconarius venustus group, as is shown by the structure of the 


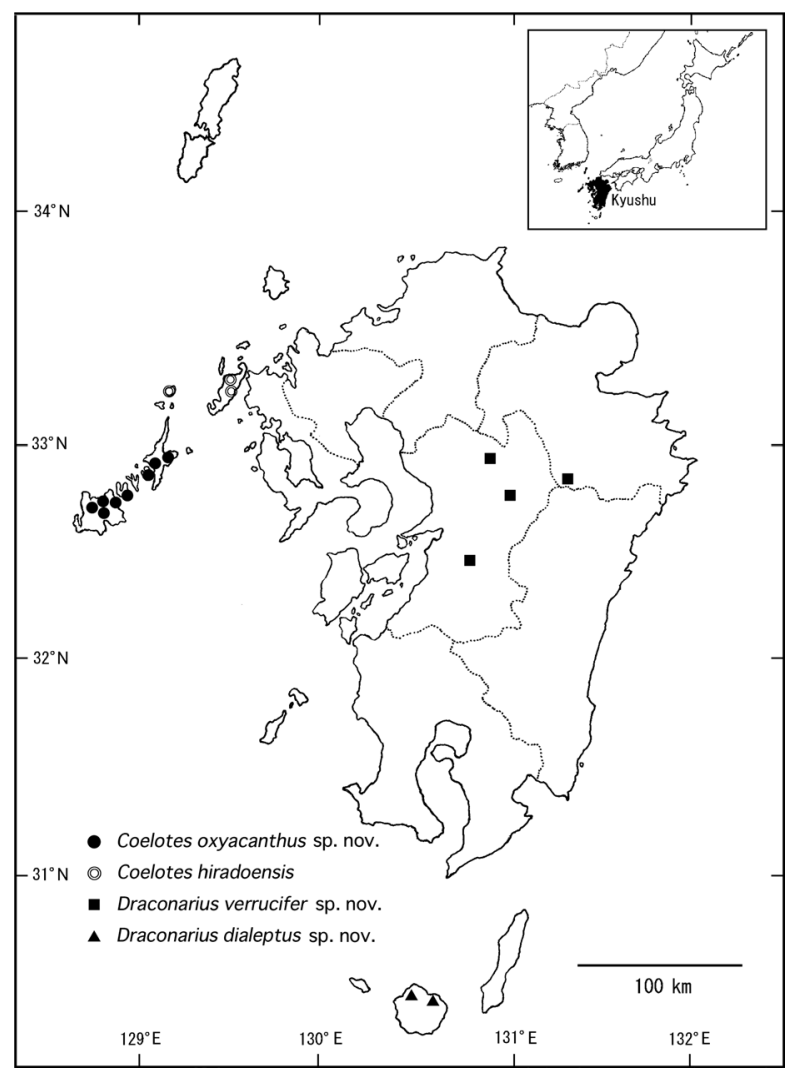

Fig. 6. Map of Kyushu, Japan, showing the distribution of Coelotes oxyacanthus sp. nov. Draconarius verrucifer sp. nov., D. dialeptus sp. nov., and C. hiradoensis Okumura and Ono, 2006, also showing geographical replacement of C. hiradoensis by C. oxyacanthus.

endogynum. For example, it resembles Draconarius venustus Ovtchinnikov, 1999 (q.v.), the type species of this genus, as well as D. pakistanicus Ovtchinnikov and Inayatullah, 2005 (q.v.), D. naranensis Ovthinnikov and Inayatullah, 2005 (q.v.), and D. latellai Marusik and Ballarin, 2011 (q.v.) in having enlarged and convoluted copulatory ducts and small accessorial glands situated in the central portion of the endogynum. Draconarius verrucifer sp. nov. is distinguished from the above four species by the absence of epigynal teeth and the presence of a single, tiny protrusion.

Description. Female (holotype). Total length 4.5; carapace 1.8 long, 1.4 wide; abdomen 2.7 long, 1.6 wide; sternum 1.1 long, 1.0 wide. Ocular area (Fig. 5G): anterior eye row almost straight and posterior one slightly recurved in frontal view. Eye sizes: AME 0.04, ALE 0.09, PME 0.09, PLE 0.10 . Distances between eyes: AME-AME 0.03, AME-ALE 0.03, PME-PME 0.08, PME-PLE 0.05, AME-PME 0.08, ALE-PLE 0.05. MOA: anterior width 0.11 , posterior width 0.26 , length 0.21. Leg measurements: I, 6.5 (1.8, 2.3, 1.4, 1.0); II, 6.0 (1.7, 1.9, 1.4, 1.0); III, 5.7 (1.5, 1.8, 1.6, 0.8); IV, $7.9(2.1,2.4,2.3,1.1)$.

Chelicera (Fig. $5 \mathrm{H}$ ): promargin with three teeth and retromargin with two widely spaced teeth.

Epigynum and endogynum (Fig. 5E, F): epigynal plate almost circular; epigynal teeth absent, but single tiny protrusion present on center of posterior margin of epigynum; copulatory ducts close to each other, complexly convoluted several times, and externally looking like gill slits of sharks; spermathecae situated in posterolateral parts of endogynum.

Coloration: carapace yellowish brown, with indistinct radial flecks; dorsum of abdomen yellowish gray with indistinct chevrons; sternum yellowish brown; chelicerae brown; maxillae and labium yellowish brown; legs yellowish brown without ring flecks.

Distribution. Kumamoto and Oita Prefectures (Fig. 6).

Etymology. The specific name is a Latin adjective (-fer, -fera, -ferum), derived from verruca, "a wart", and the suffix -fer, "bearing, carrying", referring to the small protrusion of the epigynum in the new species.

Remark. The new species is characterized by having a single protrusion located in the central region of the posterior margin of the epigynum. Although the male is unknown, this new species can be easily distinguished from the other coelotine spiders by its unique female characteristics as mentioned above.

Draconarius dialeptus sp. nov. [Japanese name: Yaku-chibi-yachigumo] (Fig. 7A-D)

Material examined. Holotype: NSMT-Ar 9867, male, Kusugawa, $230 \mathrm{~m}$ alt., Yaku Island, Kagoshima Prefecture, $\left(30^{\circ} 39.7^{\prime} \mathrm{N}, 130^{\circ} 58.8^{\prime} \mathrm{E}\right) 5$ January 2008.

Paratype: NSMT-Ar 9868, male, Nagata, Yaku Island, Kagoshima Prefecture, 3 January 2008.

Non-type specimen: same data as the holotype, 1 male.

Diagnosis. The new species is similar to D. venustus Ovtchinnikov, 1999 (q.v.), the type species of this genus, in having two retromarginal teeth on the chelicera, an elongated cymbial furrow, a developed conductor, and a long embolus. The new species also resembles $D$. aspinatus (Wang, Yin, Peng and Xie, 1990), and D. bituberculatus Wang, Yin, Peng and Xie, 1990 in the absence of a patellar apophysis, but it can be distinguished from the latter two species by the structure of the conductor. That of $D$. dialeptus is tripartite, but that of D. aspinatus is spiniform and broad, and that of D. bituberculatus is posteriorly extended (Wang et al. 1990; Wang 2003).

Description. Male (holotype). Total length 4.0; carapace 2.0 long, 1.4 wide; abdomen 2.0 long, 1.2 wide; sternum 1.0 long, 0.9 wide. Ocular area (Fig. 7C): both anterior and posterior eye rows almost straight in frontal view. Eye sizes: AME 0.04, ALE 0.10, PME 0.11, PLE 0.10. Distances between eyes: AME-AME 0.02, AME-ALE 0.01, PMEPME 0.05, PME-PLE 0.02, AME-PME 0.07, ALE-PLE 0.03. MOA: anterior width 0.10 , posterior width 0.27 , length 0.22 . Leg measurements: I, 7.0 (1.9, 2.4, 1.6, 1.1); II, 6.2 (1.7, 2.0, 1.5, 1.0); III, 5.9 (1.6, 1.9, 1.6, 0.8); IV, 8.1 (2.1, 2.5, 2.4, 1.1).

Chelicera (Fig. 7D): promargin with three teeth and retromargin with two widely separated teeth.

Palpus (Fig. 7A, B): patellar apophysis nearly reduced; LTA large, with dorsal projection; RTA rounded at tip; cymbium narrow; cymbial furrow elongate, occupying threefourths of cymbial length; median apophysis spatulate, 


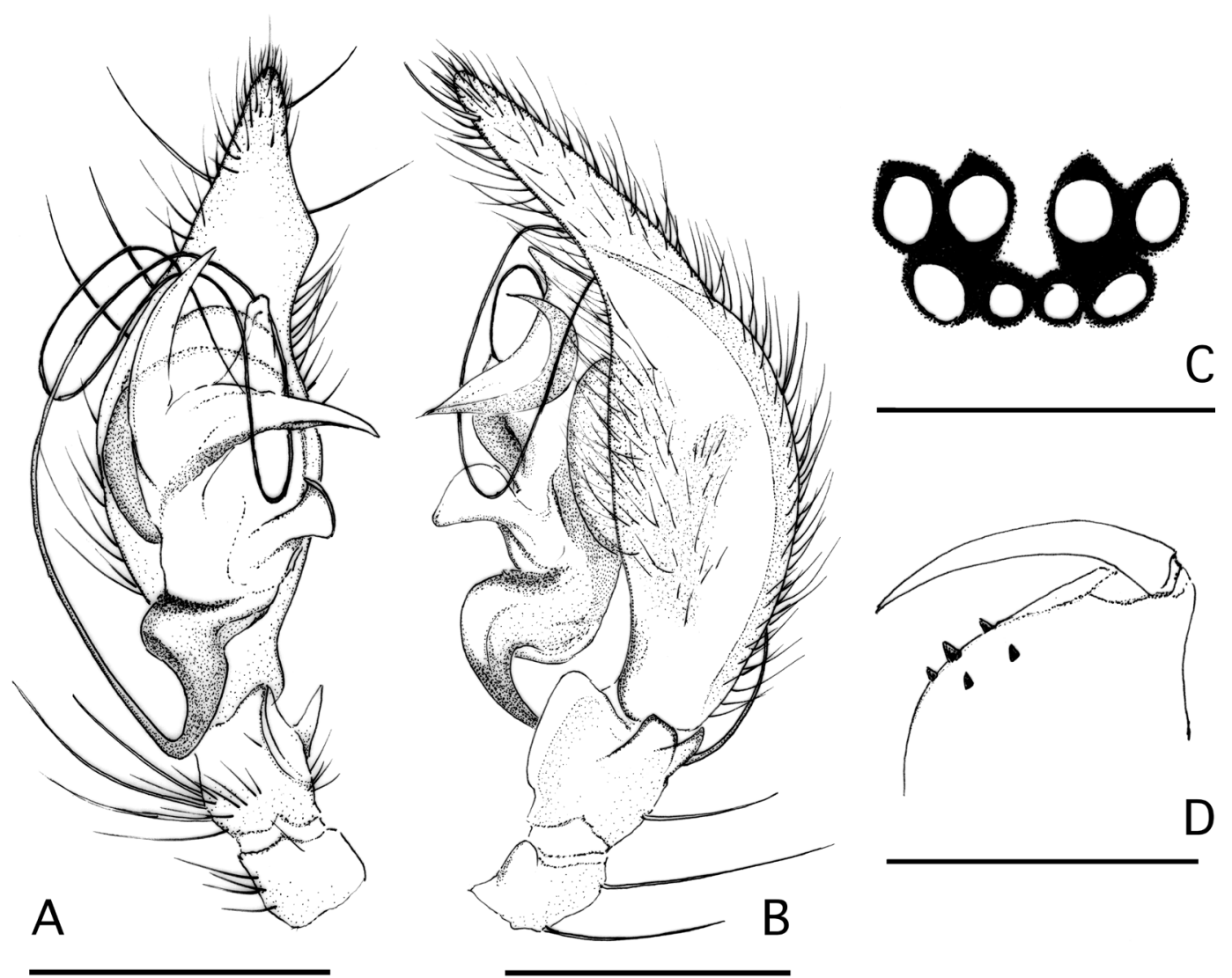

Fig. 7. Draconarius dialeptus sp. nov., NSMT-Ar 9867, holotype, male. A, Male palpus, ventral view; B, same, retrolateral view; C, ocular area, frontal view; D, left chelicera, ventral view. Scales: $0.5 \mathrm{~mm}$.

slightly curved at tip; conductor large, pointed and tripartite; embolus extremely long, complexly curved.

Coloration: carapace yellowish brown, with indistinct radial flecks; dorsum of abdomen grayish brown, with yellowish-brown chevrons; sternum pale yellow; chelicerae, maxillae, and labium yellowish brown; legs yellowish brown without ring flecks.

Distribution. Yaku Island, Kagoshima Prefecture (Fig. $6)$.

Etymology. The specific name, an adjective, is derived from Classical Greek, meaning very small and refers to the extremely small size of the new species.

\section{Acknowledgements}

I wish to express my sincere thanks to Dr Hirotsugu Ono (Tsukuba) for reading the manuscript and for helpful suggestions. My heartfelt thanks are due to Dr Yoh Ihara (Hiroshima) and Mr Teruo Irie (Kumamoto) for providing specimens of Coelotes verrucifer sp. nov. and C. iriei sp. nov. I also thank Mr Naoki Koike (Kyoto) for providing valuable information concerning the new species described herein.

\section{References}

Marusik, Y. M. and Ballarin, F. 2011. A new species of Draconarius
Ovtchinnikov, 1999 (Araneae, Amaurobioidea, Coelotinae) from northern Pakistan. Zootaxa 2739: 27-32.

Nishikawa, Y. 1973. Two new spiders of the genus Coelotes (Araneae: Agelenidae) from Japan. Faculty of Letters Review Otemon Gakuin University 7: 75-81.

Nishikawa, Y. 2009. A new genus and 44 new species of the family Coelotidae (Arachnida, Araneae) from Japan. Pp. 51-69. In: Ono, H. (Ed.) The Spiders of Japan. Tokai Daigaku Shuppankai, Tokyo. [In Japanese]

Okumura, K. 2007. Three new species of the subfamily Coelotinae (Araneae: Amaurobiidae) from Kyushu, Japan. Acta Arachnologica 56: 85-90.

Okumura, K. 2010. First description of the male of Platocoelotes uenoi (Yamaguchi \& Yaginuma 1971), n. comb. and a new record of Draconarius coreanus (Paik \& Yaginuma 1969) (Araneae: Coelotidae) from Kyushu, Japan. Acta Arachnologica 59: 5-7.

Okumura, K., Nishikawa, Y. and Ono, H. 2011. Two new species of the genus Tegecoelotes (Araneae: Agelenidae) from Chubu and Chugoku Districts, Honshu, Japan. Acta Arachnologica 60: 47-50.

Okumura, K. and Ono, H. 2006. Two new species and a new synonymy of the subfamily Coelotinae (Araneae: Amaurobiidae) from Kyushu, Japan. Acta Arachnologica 55: 51-58.

Okumura, K., Shimojana, M., Nishikawa, Y. and Ono, H. 2009. Coelotidae. Pp. 174-205. In: Ono, H. (Ed.) The Spiders of Japan. Tokai Daigaku Shuppankai, Tokyo. [In Japanese]

Ovtchinnikov, S, V. 1999. On the supraspecific systematics of the subfamily Coelotinae (Araneae, Amaurobiidae) in the former USSR fauna. Tethys Entomological Research 1: 63-80.

Ovtchinnikov, S, V. and Inayatullah, M. 2005. Two new spider species of the genus Draconarius (Araneae, Amaurobiidae, Coelotinae) from Pakistan. Vestnik Zoologii 39: 85-88. 
Platnick, N. I. 2012. The World Spider Catalog, version 12.5. American Museum of Natural History. Available at http://research.amnh. org/entomology/spiders/catalog/index.html (18 June 2012).

Wang, J.-F., Yin, C.-M., Peng, X.-J. and Xie, L.-P. 1990. New species of the spiders of the genus Coelotes from China (Araneae: Agelenidae). Pp. 172-253. In: Yin, C.-M. and Wang, J.-F. (Eds) Spiders in China: One Hundred New and Newly Recorded Species of the Families Araneidae and Agelenidae. Hunan Normal University Press, Changsha.

Wang, X.-P. 2003. Species revision of the coelotinae spider genera $\mathrm{Bi}$ fidocoelotes, Coronilla, Draconarius, Femoracoelotes, Leptocoelotes, Longicoelotes, Platocoelotes, Spiricoelotes, Tegecoelotes, and Tonsilla (Araneae: Amaurobiidae). Proceedings of the California Academy of Sciences 54 (26): 499-662. 